\title{
Rational Action
}

\section{Pamela E. Oliver}

This is a preprint of an article appearing in Donatella Della Porta and Mario Diani, eds., The Oxford Handbook of Social Movements. 2016 Oxford University Press. Online at http://www.oxfordhandbooks.com/view/10.1093/oxfordhb/9780199678402.001.0001/oxfordh b-9780199678402 or available in print from https://global.oup.com/academic/product/theoxford-handbook-of-social-movements-9780199678402?cc=us\&lang=en\&

\section{Abstract}

This chapter challenges stereotypical representations of rational approaches as necessarily based on isolated individuals. It argues instead that the real contributions of rational action theory to understanding social movements have been made at the group level, where simplifying and even simplistic assumptions about individual motivations have permitted genuine insights into the differences between different kinds of actions and the differences between groups. There is not one dynamic of collective action, but many dynamics. Providing the collective good is unproblematic in some situations and impossible in others. In some contexts, incentive systems help promote collective action, while in other parts of the space, incentive systems can actually lead people to enforce outcomes that no one wants. A theory of strategic agency is needed to understand why collective action takes different forms in different contexts and how actors can make choices that change the strategic game they are playing.

Keywords: collective action problem, critical mass, free-riding, group size, incentives, strategy

Attempts to assess the contributions and value of rational action approaches to studying social movements have to negotiate the thicket of matters of ideology and identity among scholars of social movements and the shifting significations they attach to the meaning of the words "rational" and "rational action." Some scholars have attached positive value to the word "rational" and have rejected claims that social movements were mindless or ill-conceived emotional responses to strain (e.g., Schwartz 1976). Others attach negative value to rationality and associate it with the disciplinary invasion of sociology by economics, unfettered capitalism, isolated individualized selfishness, a rejection of social structure, and patriarchy (e.g., Ferree 1992). Those who attach negative value to the term "rational action" typically use it to refer only to calculations by isolated selfish individuals and rational action theory as a single hegemonic project. By contrast, those who use the term positively tend to refer to the broader tradition of work that flowed from engagement with rational action ideas and rational action theory as a set of well-bounded tools for constructing explanations (Lichbach 2003; Opp 1999, 2009, 2000).

The assertion that all people pursue their individual self-interest is either empirically false or tautological, depending on how narrowly the concept of self-interest is defined. Similarly tautological and untestable are the symbolic interaction dicta that people act toward things 
based on the meaning things have for them, that meanings are derived from interaction, and that people engage in interpretive processes (Blumer 1969). Also tautological is Ferree's "feminist and social constructionist" alternative to rational action's core assumption: "all values, including those that appear to be 'natural' and 'objective' rest in social experience of some sort" (Ferree 1992). Ditto the core orienting premises of resource mobilization, political process, or any other general theory. Smelser (1992) argues that a theory that explains everything is a theory that explains nothing and may be considered degenerate. But tautological theoretical premises may be very useful if they lead to previously unrecognized insights into social processes, or even if they offer orderly accounting schemes for inventorying relevant factors.

This chapter ignores ideological debates about whether people are or are not rational, whether rationality is a stalking horse for patriarchy, and the political implications of assumptions of market rationality for social policies. It does not assume that everybody is rational, nor that individuals are isolated. It argues instead that the real contributions of rational action theory to understanding social movements have been made at the group level, where simplifying and even simplistic assumptions about individual motivations have permitted genuine insights into the differences between different kinds of actions and the differences between groups. These insights can be coupled with a theory of strategic agency to provide tools for understanding why collective action takes different forms in different contexts and how actors can make choices that change the strategic game they are playing. The real contributions of rational action theory cannot be reduced to slogans that fit on placards, and understanding these contributions requires a willingness to engage complexity and contingency.

\section{Olson and Collective Action}

Any discussion of rational action theory in social movements must begin with the provocative claim by economist Mancur Olson's The Logic of Collective Action (1965) that "rational, selfinterested individuals will not act to achieve their common or group interests" (2, emphasis added). Olson made social scientists realize that there was something essential to study in what happens in the gap between collective interests and collective action. His impact on social science was enormous, even though critics quickly showed that his sweeping verbal claims and nods to mathematics notwithstanding, whether it is rational or not for an individual to contribute to collective action depends very much on the properties of the situation (e.g., Frohlich et al. 1975; Frohlich and Oppenheimer 1970). Oliver (1993) provides a review of this early literature. Olson lumps together several dimensions of action situations that need to be disentangled. The central issue is non-excludability, which means that if a collective good is provided, there is no way to keep non-contributors from enjoying the good. Everybody experiences the same level of air pollution, regardless of how much greenhouse gas they personally exude; everybody experiences the same level of non-discrimination in housing, regardless of whether they personally participated in a civil rights march or not. Nonexcludability throws a wrench in the usual microeconomic model of market pricing where people "buy" just the right amount of a good to maximize their satisfaction, subject to a resource constraint. The engine of Olson's mathematical argument is that each individual's share of a collective good-and thus her payoff-goes down with the number who share the good, while the cost of providing the good goes up with the number who share in it. Thus, he argues intuitively, people will not contribute to large-group goods because individual 
contributions have to be divided up among too many free-riding recipients. At first blush, this argument seems to hold a lot of water. The large group problem certainly seems to adhere to air pollution or voluntary contributions to national defense.

The problem with Olson's analysis is that most non-excludable goods also have high levels of jointness of supply, which means that the cost of provision is the same regardless of the number who enjoy the good. It costs a certain amount to build a bridge, for example, whether it will be used once or thousands of times. This is especially important because collective goods provided through political systems have high jointness of supply: the cost of lobbying or political pressure does not usually go up with the number of people who benefit from the law. Extensive levels of environmental cleanup were produced by activists lobbying for new laws to force businesses to reduce pollution (Mitchell 1979). Wealthy individuals or businesses often find it in their interest to lobby for a bill that benefits them and are typically indifferent as to whether the bill also benefits (or hurts) others.

What Olson referred to as one problem - the free rider problem-is really two quite different problems. One is the noticeability or efficacy problem: Can the individual actually do (or afford to do) anything that would make a noticeable difference in the collective good? This is the core of Olson's "large group" problem. No single individual can stop global warming through their own personal lifestyle choices. No single individual can create racial justice or world peace. The other problem is the real free rider dilemma: if there are more people willing to pay for a nonexcludable jointly supplied good than are necessary for its provision, there may arise a "small group" strategic gaming problem where each hopes that someone else will pay the cost. This happens every day when roommates dodge housework and hope that someone else will wash the dishes. Similarly, the free rider dilemma is a real issue in social movement groups when it comes to dividing labor for unpleasant tasks like cleaning up after a meeting. But because of jointness of supply, there may be free riding with no dilemma. Wealthy patrons often pay for collective benefits like concert halls and are quite happy to let other people listen to the music. Some social movements have been underwritten by wealthy patrons who cared about the issue and were quite happy to let other people benefit, too. Free riding stymies collective action if people fail to act because they hope someone else will do the job. But free riding and efficacy are not the same problem and they have different solutions.

Olson is right that collective goods are rarely provided through the unorganized independent actions of isolated people whose individual contributions are too small to make a difference. But flipping his argument around (and consistent with his discussion of what he calls small groups), the implication is that collective goods can readily be provided when actors are coordinated or when the strategy for providing the good involves working through the political system. That is, a serious engagement with the logical consequences of Olson's arguments leads directly to recognizing the importance of organization and strategy.

\section{Impact of Olson on the Study of Social Movements}

By the early 1970s, it was already recognized that "Olson's problem" was not a single problem and that the dilemmas that existed under the assumption of independent isolated decision makers could be readily solved if people could talk to each other and coordinate their actions. Early social movement writers in the rational action tradition ignored these formal results and 
largely took Olson's claims at face value, using them as theoretical grounds for stressing the importance of groups and organization. That is, the most direct and substantial impact of rational action arguments on actual social movement theory was not an emphasis on models of isolated individuals but, to the contrary, an emphasis on the problem of mobilization and its dependence on organizations, social networks, and social structure.

One of the first works on social movements to deeply engage the implications of Olson's arguments was Oberschall's Social Conflict and Social Movements (1973). Oberschall built his theory by putting the character of a latent group's social organization at the center of the theory and developed hypotheses for how mobilization varies depending on the social organizational structure. Writing a few years later, Oberschall (1978) used the label "solidarity theory" for writers like Tilly who "stress that conditions that lead to violent protest are essentially the same as those that produce other forms of collective action; view all forms of collective action, including violent ones, as essentially purposeful, rational pursuits or defenses of collective interests ...." because, for him, rational action encompasses issues of networks and collective solidarity.

McCarthy and Zald's first resource mobilization paper (McCarthy and Zald 1973) stressed the importance of resources for movements but also of structure, saying, "This view does not necessarily deny the existence of grievances. It stresses the structural conditions that facilitate the expression of grievances" (1). This paper mentioned Olson only in a footnote (fn. 14 at 22) that argued that resources made it relatively easy to provide incentives for action. However, by the time they published their programmatic statement in the American Journal of Sociology (McCarthy and Zald 1977), McCarthy and Zald had moved Olson to the foreground, saying: "The resource mobilization perspective adopts as one of its underlying problems Olson's (1965) challenge: since social movements deliver collective goods, few individuals will 'on their own' bear the costs of working to obtain them. Explaining collective behavior requires detailed attention to the selection of incentives, cost-reducing mechanisms or structures, and career benefits that lead to collective behavior (see, especially, Oberschall 1973)." Tilly's theoretical statement From Mobilization to Revolution (Tilly 1978) similarly give central place to the problem of networks and social organization of challenging groups with his concepts of "catness" and "netness."

Thus, social movement theory emerged from its encounter with Olson as a theory of mobilization, as a theory of the social stuff that happens in the middle between grievances or interests or goals on the one hand and action in pursuit of those ends on the other. Virtually all of the impact of rational action theory in the actual study of social movements was to focus attention on the matter of networks and organization and social structure. The idea that social structure matters is argued by the most ardent partisans of rational action theory. For example, Hechter (1992) argues that game theory alone is insufficient without direct consideration of the actual social arrangements and mechanisms that structure the information available to participants while Hechter and Okamoto (2001) build their discussion of minority group formation around a rational action consideration of free riding, but also stress the importance of identity formation and institutional structures. 


\section{Incentives}

Olson argued for the importance of what he called selective incentives (also known as side payments), that is, benefits offered to individuals that are contingent on participation, or costs that are imposed on non-participants. "Only a separate and selective incentive will stimulate a rational individual in a latent group to act in a group-oriented way .... The incentive must be 'selective' so that those who do not ... contribute to the attainment of the group's interest, can be treated differently from those who do" (Olson 1965: 51). Although Olson thought only about the impact of incentives on individuals, the incentive idea rapidly led to consideration of issues of social organization.

Drawing on ideas about incentives in organizations originally written before Olson's book was published (Clark and Wilson 1961), James Q. Wilson (Wilson 1974) directly engaged and repacked Olson's incentive arguments by attacking the idea that incentives could only be material. In addition to material incentives, there are two other broad types that were wellrecognized to affect organizational participation: solidary (tied to other people) and purposive (tied to internal motivations of morality or ethics). Solidary incentives include things like simple sociability from being with others, other people's approval for one's actions, and respect or honor for leadership roles. When solidary incentives are important, it matters who one is with and how other people feel about the collective action. Some solidary incentives have jointness of supply where everyone can share in them without diminishing the value to anyone else, such as when people simply enjoy being with other people in the action, or when friends and family approve of the participation. Other solidary incentives are more like private goods, like the value of being recognized as a leader.

A purposive or moral incentive is the benefit of participating (or not) that arises from within a person such as when a person's sense of personal morality or ethnics depends on doing what is right. Purposive incentives are typically linked to religious, ethical, or political philosophies and identities. Carden (1978) points to purposive incentives as one of the central features of social movements and voluntary action more broadly: because people are motivated to do what seems important to them, movements often focus on actions that fit the participants' sense of rightness, whether or not they promote the collective good in some instrumental way. The idea of a purposive or moral incentive is akin to the idea of identity as a motivator, that a person participates because they are that kind of person.

The concepts of solidary and purposive selective incentives provide a way of talking within a rational action framework about the importance of social influence, ideology, identity, and solidarity. Treating these as types of incentives permits them to be treated alongside collective goals and material incentives as factors that, in combination, affect how people act. It permits a consideration of how different factors might reinforce each other sometimes but be balanced against each other or run at cross purposes in others. Of course, other theories also address these issues, and rational action theory itself has little to offer as an explanation for why people want to be with a particular group or have a particular ideology or identity that motivates them, although some of the theories of social influence (discussed later) do offer some explanations. The point is not that the idea of incentives makes other theoretical approaches unnecessary or irrelevant, but rather that rational action theory has places where the insights from other types of theory can be plugged in and merged. For example, Melucci's $(1985,1988,1995)$ arguments 
about the importance of symbolism and identity in movements are not rational action theories by any means, but Melucci's insights can be linked with rational action ideas to treat symbolic expression as a desirable outcome or goals, or the very process of constructing the collective actor as relevant to whether a solidary or purposive incentive exists for action.

\section{Action in Crowds}

In the wake of the Black urban riots, the social scientists collaborating on the report of the National Advisory Commission on Civil Disorders (Kerner et al. 1968) and at least half a dozen other studies by sociologists and political scientists published between 1968 and 1970 (cited by Marx 1970) argued that the riots should fundamentally be understood as protests against racial discrimination, police brutality, and adverse social conditions. Such studies cited evidence about differentiation of behaviors within an event, choices of targets, and observable processes within crowd events, and verbal claims of the rioters. Authors argued that crowd participants were no less rational than the social scientists studying them and that people's actions could be understood as rule-governed or ends-oriented behavior under conditions of interdependence (e.g., Berk 1974). This line of argument had become so strong by 1970 that Gary Marx was moved to write "Issueless Riots" (Marx 1970), arguing that not all riots were instrumental, and offering hypotheses about the differences between instrumental and non-instrumental riots.

Much of the theorizing that derives from this tradition gives little attention to motives for participation, but instead draws on research that found little evidence of heightened emotionality or new beliefs in self-reports of decisions to riot, but only information about when and where the riot was occurring (e.g., Singer 1968; Singer et al. 1970) and focuses on the problem of mobilization, in line with the resource mobilization emphasis on social movements. For example, McPhail and his colleagues stressed the importance of the mobilization process itself as central in crowd action (McPhail 1969, 1971, 1991; McPhail and Miller 1973; McPhail and Wohlstein 1983). In his comprehensive review and critique of theorizing about crowds, McPhail (1991) gives many examples of cases demonstrating clear evidence of planning, organization, and goal-oriented behavior in episodes of crowd violence in lynchings and riots, and argues for the importance of recognizing what he later calls "the dark side of purpose" (McPhail 1994).

Formal models of crowd behavior from the 1970s focus on how people's decisions are affected by others' actions. Building on arguments by Schelling (1973) and Berk (1974), Granovetter (1978) makes no assumption about motivations except that people's willingness to join a collective behavior depends on how many others are already acting and that each person has a threshold $X$ such that they will not join if the number of others is below $X$ and will join if the number of others is $X$ or above. He shows that whether collective action cascades or stalls depends on the heterogeneity of the group and the presence or absence of gaps in the distribution of thresholds. Oliver (1993) shows that the engine in Granovetter's models is actually the proportion of a group's members who are self-starters (i.e., have thresholds of zero). Granovetter and Soong (1983) provide further elaborations. Macy (1991) reworks Granovetter's models in stochastic learning terms, finding similar results. The image in these models is that collective action happens not from coordination and planning, but spontaneously through local interactional influence. This is not entirely different from some of the older 
collective behavior models of contagion, except that this attention to others' behavior is treated as unproblematic and not in need of a psychological explanation.

\section{The Usefulness and Ultimate Inadequacy of One- and Two-Person Models}

Empirical research grounded in collective action accounting models has demonstrated that participants tend to have collective rationality in the sense that they value the goals of the movement and to believe that the collective action will promote those goals (Muller and Opp 1986; Opp 1990, 1988; Finkel and Muller 1998). However, free riding as a psychological dynamic does not seem to arise. Individual personal gain is less predictive of action than collective gain (Muller and Opp 1986). Costs or constraints matter (Klandermans and Oegema 1987) and incurring the costs of repression can hinder action (Opp 1994; Opp and Roehl 1990). Consistent with ideas of social or purposive incentives, participants are more likely than non-participants to identify with movement groups or to have network ties to participants or to say people approve of their participation (Finkel et al. 1989; Klandermans 2002; Klandermans and Oegema 1987; Klandermans et al. 2008).

Work grounded in the rational action tradition has also provided clear evidence for the social construction of costs and benefits, as well as group identities. Movement participants actively resist attempts to get them to divorce the impact of their individual actions from that of the group as a whole and are motivated by the perceived efficacy of the collective action, not the marginal difference their own showing up might make (Klandermans 1988; Klosko et al. 1987; Muller and Opp 1986); studies also find that participants perceive higher costs of acting than non-participants do (Muller and Opp 1986; Opp 1990). People's beliefs about the costs and benefits of collective action change after their participation (Finkel and Muller 1998) and the experience of being repressed leads to a greater since of grievance (Opp 1994, 2004; Opp and Roehl 1990).

Overall, empirical research inspired by the rational action tradition has shown the importance of the group identities and collective orientations as well as of instrumental considerations of the consequences of actions. However, formal rational action models grounded in predicting the behavior of one person at a time have not helped to generate new theoretical insights.

Although some early works in social movements included individual-level equations for rational choices, these equations did no analytic work except as simple accounting schemes or heuristics to support a verbal argument. An individual-level rational action model would take a form like $\mathrm{V}(\mathrm{a})=\Delta \mathrm{B} \mid \mathrm{a}-\mathrm{C}, \mathrm{C}<\mathrm{R}$ or maybe $\mathrm{V}(\mathrm{a})=(\Delta \mathrm{p} \mid \mathrm{a}) \mathrm{B}-\mathrm{C}, \mathrm{C}<\mathrm{R}$, where $\mathrm{V}(\mathrm{a})$ is the value of doing action $\mathrm{a}$, $\Delta B \mid a$ is the change in the benefit or value given that action a is done, $C$ is the cost of doing action $\mathrm{a}$, and $\mathrm{R}$ is the resource constraint on $\mathrm{C}$. In the second specification, $\mathrm{B}$ is a benefit and it is multiplied by $\Delta p \mid a$, the change in probability of getting $B$ if action a is done. If $B$ and $C$ are in the same metric, a number $V(a)$ can be calculated and a prediction can be made that the likelihood of doing a will be a function of $\mathrm{V}(\mathrm{a})$.

The trouble is that $B$ and $C$ never are in the same metric and in addition there are often multiple benefits and multiple costs that all have different metrics. If things don't have common metrics, they cannot be added. Benefits like civil rights and costs like marching or getting beaten just don't have the same metrics. Moreover, the conditional difference $\Delta B \mid a$ or $(\Delta p \mid a) B$ itself is 
generally not a static number but rather a complex function of the inputs from other people in the situation. In short, it is not actually possible to write an equation for individuals' decisions that would yield any kind of determinate or meaningful number that would predict their behavior. Instead, individual-level equations are used only heuristically to guide a verbal discussion of the kinds of factors that are expected to influence behavior, and as a guide to the kinds of things that should be considered. What do people think the benefits are? Do they think the action is an efficacious way to achieve the benefit? Does the person have the resources to incur the cost that is big enough to produce the desired benefit? Does the expected change in benefit outweigh the cost?

Similarly, $2 \times 2$ game theory payoff matrices treat "the individual" and "the group" as a unitary actor whose decision considerations can be summarized into one net payoff. The free rider problem has been equated to the prisoner's dilemma, in which an individual always gains more by defecting regardless of the other's action, but both actors will receive more if both cooperate than if both defect, and there have been many discussions of the factors that affect social movements that are organized around the solutions to this dilemma (see Lichbach 1995). As Lichbach's exhaustive discussion shows, the $2 \times 2$ matrices provide a vocabulary for talking about strategic dynamics and the wide variety of solutions to the game that are possible, but no formal tools for deciding which strategic situation a group actually is in. Further, collapsing "the group" and treating it as "the other" means that the $2 \times 2$ game is really a unitary actor model. As such, it provides no tools for attending to issues of group size or group social organization or network structure. In addition, many collective action situations are not prisoner's dilemmas but assurance games (individuals will gain more by cooperating as long as they are sure everyone else is cooperating too) or coordination games (individuals gain as long as their behavior matches others' behavior).

Even seemingly more-complex models resolve to unitary actors and provide only heuristic guidance. For example, Ahlquist and Levi (2013) develop a rational action model within the theory of clubs in which there is enough profit to be made from group action to pay a leader extra to provide the coordination, and use this model as a foil for discussing the differences between corrupt unions whose leaders extract material payments and political unions whose leaders extract participation in radical political activities, starting from the premise that there is a finite "rent" to be paid to leaders one way or another. But the formal model is not tied to the rich historical detail of their case studies, nor does their later discussion of the endogeneity of radical ideology and the importance of governance structures make its way back into any refined formal theoretical model.

\section{Critical Mass Theory and Social Solutions to Social Dilemmas}

The metaphor of the critical mass has been used at least since the 1960s by social movement activists to refer to the number of people who could get some kind of protest movement going. The first newsletter of the Collective Behavior and Social Movements section of the American Sociological Association was called the Critical Mass Bulletin. Sullivan (1977) discusses how the critical mass in riots involves not only sheer numbers but the social relations among people. In a series of articles collected into their book, Marwell and Oliver (1993) picked up on the metaphor to use the phrase "critical mass" as a label for theories of the ways in which a few individuals 
can create the conditions for providing collective goods to a whole group. This built on discussions of what is often called the second order collective action problem (Oliver 1980), that is, why should someone pay to provide selective incentives to get others to contribute to a collective good? Because positive incentives are paid to cooperators but negative incentives to non-cooperators, they have different cost structures and are, thus, associated with different kinds of collective actions. Rewards are efficient for motivating a few to act to benefit the many, while the threat of punishment is efficient for maintaining unanimous action. Thinking about incentive structures made it obvious that the formal problem of incentivizing collective action in a group could not be correctly analyzed with individual-level models but required specific attention to the nature of the collective action and the nature of the group.

While its model of individual choice is oversimplified, the rational action framework has led to a careful recognition and specification of the great diversity of collective action problems. As highlighted by Elinor Ostrom (1998), the key insight of Oliver and Marwell's line of work called critical mass theory is their rejection of monocausal arguments when they say: "This is not to say that general theoretical predictions are impossible using our perspective, only that they cannot be simple and global. Instead, the predictions that we can validly generate must be complex, interactive, and conditional" (Marwell and Oliver 1993: 25). To repeat, the most important lesson of critical mass theory specifically and rational action theory more broadly is that there is no one-size-fits-all simple theory of collective action. Useful theory is not placard-sized slogans about individualism, but rather entails complex, interactive, and conditional arguments about the differences among groups, actions, and situations.

For example, instead of a slogan-sized debate about whether group size has a positive or negative effect on collective action, Oliver and Marwell (1988, also Marwell and Oliver 1993: ch. 3 ) argue that the nature of the group size effect interacts with the level of heterogeneity and the level of jointness of supply. Paradoxically, when groups are heterogeneous, the size of the critical mass of people who have both the interest and resources to be willing to act together to provide a jointly supplied collective good may actually be smaller in a larger group. Intuitively, this can happen because a more heterogeneous group has greater inequality and thus is more likely to have a few wealthy benefactors. This is a complex and contingent finding about interactions effects among the type of good (degree of jointness of supply), group size, group heterogeneity, and the correlation between interests and resources and not (contra too many sloganized citations to their work) a simplistic bivariate assertion that either group size or heterogeneity promote collective action. Or, again, in place of Olson's under-theorized and undifferentiated "free rider problem," Oliver and her colleagues (Oliver et al. 1985) stress the importance of the exact form of the production function that relates inputs of units of collective action to outputs of units of collective good. When production functions are non-linear, people's choices are interdependent, in that each person's best choice depends upon what others are doing. They contrast the convex or diminishing returns case with the concave or increasing returns case, showing that the critical mass plays a different role in each: in the convex case, the most interested and resourceful actors provide the good while others free ride, while in the concave case the interested and resourceful actors solve the start-up problem and bring others into the collective action. Oliver and Marwell devoted most of the rest of their work on the critical mass to organizer-centered models in the concave case that assumed that a small group 
of self-starters were absorbing the second-order costs of recruiting or coordinating others for collective action (Marwell and Oliver 1993; Marwell et al. 1988; Prahl et al. 1991). These models attend to group heterogeneity, social network properties, and the costs of information and communication, and find complex interactions among these factors leading to thresholds that partition the response space into areas with different dynamics.

This investigation of complexity and contingency is the main thrust of most formal sociological work on collective action. Heckathorn (1996) dug into the second order problem, showing that production functions for collective goods and production functions for incentive systems could interact in complex ways to generate many different dynamic patterns. Incentives can promote cooperation that benefits everyone, but they can also lead people to do things that are against their self-interest or to motivate or police a revolt against a collective effort. Heckathorn argued that parameters for production functions and incentives jointly define a space divided by thresholds into five regions with different strategic dilemmas that are equivalent to the five games in a standard two-person game matrix and that these five regions of the strategy space correspond to five distinct political ideologies for reconciling potential conflicts between individual and collective interests Heckathorn (1998). Kitts $(2006,2008)$ builds on Heckathorn's work to show how incentives can affect the development of norms that either promote or hinder collective action, again depending on complex and interactive conditions.

One line of work in the rational action tradition actually replaces the individual-level assumption of a forward-looking rational actor with a backward-looking adaptive learner who responds to the current level of reward or punishment in the environment (e.g., Macy 1990). Such models produce both the thresholds characteristics of critical mass situations and the division of labor consistent with free rider arguments.

In short, this line of work has demonstrated that there is not one dynamic of collective action, but many dynamics. Providing the collective good is unproblematic in some situations and impossible in others. In some contexts, incentive systems help promote collective action, while in other parts of the space, incentive systems can actually lead people to enforce outcomes that no one wants. For people interested in the concrete problems of social movements, the lesson of these theoretical exercises is that problems of collective action are not typically simple, and incentives can be perverse. But the situation is not theoretically anarchic: there are conceptual tools for distinguishing among different situations.

\section{Action in Networks}

A substantial body of work in the rational action tradition makes no assumption at all that people are selfish or individually rational, but instead examines the effects of influence or sideways processes wherein people's choices are affected by the behavior of the people around them, either through norms of fairness and balance or through influence. Social networks affect these influence processes. Consistent with critical mass ideas, most of these models exhibit threshold effects and complex interactions among different factors. The Gould (1993) model assumes fairness norms and finds that the location of an initial group of unconditional cooperators in the network interacts with network density and group size. In a similar vein, Kim and Bearman (1997) assume that people value both the collective good and equality of 
contributions, finding that collective action occurs where network power and interests are positively correlated.

A growing body of research investigates network effects, generally finding that influence and new or initially unpopular ideas spread most effectively when societies have segmented networks in which people are more likely to have social ties to people like themselves (Centola and Macy 2007; Centola et al. 2005; Centola 2013; Janssen 2011; Siegel 2009). What these formal results show, in essence, is that initially unpopular ideas can be nurtured in relatively homogeneous networks where people are protected from the influences of the larger society, and these networks can expand by influencing people at their edges. This is an important set of findings for understanding how social movement ideologies can spread.

This insight is an important one to take into empirical studies of social movements. And, again, all these models reveal that even this general theme is an interaction effect, and that the dynamics of influence vary greatly depending on both the initial distribution of opinions and the structure of networks.

\section{Strategic Dynamics}

Most theoretical and empirical attention in the study of social movements is given to mobilization processes broadly construed. But social movements are inherently relational: there is always some other collective actor in the system, either a target or an opponent, and there may also be allies or audiences. Rationalist theories of strategic action abound in the study of international relations and warfare. Despite this, relatively little formal theoretical attention in the study of social movements is given to the relationships between movements and their targets or opponents. Although formal game theory provides models of strategic interaction, most use of game theory in studies of social movements has focussed on equating the collective action dilemma to the two-person prisoner's dilemma game between an individual and "the group" in a $2 \times 2$ payoff matrix (e.g., Lichbach 1995, 1996), not to the relation between movements and their opponents or targets.

There are some two- and multi-actor models. Chong (1991) developed a supply and demand model for the interactions between movements and regimes where movements produce mobilization and regimes produce policies. Hoover and Kowalewski (1992) use simulation software to develop their own model in which dissidents and regimes have grievances and resources and third party support that respond positively, negatively, or not to the intensity and scope of the others' actions. There is a longstanding concern in both sociology and political science with the relation between protest and repression, with the core question being the balance between the "repression works" effect in which repression reducesfurther protest, and the backlash effect, in which repression increases protest by way of increasing grievance. Francisco (1995) tests two predator-prey models from mathematical biology to assess the relation between protest and repression in three cases (German Democratic Republic, Czechoslovakia, and the Palestinian Intifada) and concludes that protesters adapt to coercion by changing tactics. Pierskalla (2010) develops an extensive strategic game between the government and an opposition group with incomplete information and third-party threat, arguing that it permits identification of equilibria that result either in successful repression or escalating violence. Francisco (2010) brings a great deal of empirical evidence to bear on models 
of the strategic dynamics between dissenters and regimes, arguing that most forms of symbolic protest converge on equilibria as protesters and regimes adapt to each other, while interactions between terrorists and regimes depend upon network structures between terrorists and a larger population and the regime's ability to target terrorists without harming the surrounding population.

The idea that the relation between movements and regimes should be understood in coevolutionary terms as a process of mutual adaptation is gaining adherents. Koopmans (2005) argues for reconceiving political opportunity in co-evolutionary terms, as movements and regimes interact with and respond to each other, shaping their actions over time. Oliver and Myers (2003) employ a co-evolutionary framework and focus on carefully examining patterns in observed data about protests over time and their relation to proposed relational mechanisms, including diffusion and external or mutual reinforcement by other groups. They argue that most theories cannot account for either the spikiness of real protest data or its cycles, in which protest declines as well as rises. They show that random external reinforcement can produce the spiky patterns characteristic of real protest data and that models that presume there are several movements competing for attention/response from a common audience or regime are most capable of exhibiting the large cycles of ups and downs that characterize protest data.

Conclusions: On the Relevance of Rational Action Theory for Understanding Social Movements

Simple-minded rational action models are useless for understanding social movements, but so are simple-minded theories of any stripe. Theorists in the rational action tradition have used formal tools to show how complex collective action situations can be. Theorists and empirical researchers in the rational action tradition have themselves probed and critiqued the limits of early claims and assumptions. They have shown empirically that collective rather than individual orientations predominate in social movements. Formal theorists have shown that there are complex interactions that create qualitatively different strategic dynamics depending on the combinations of different factors. Any simplistic bivariate statement that any single factor helps or hurts collective action or the likelihood of movement success is simply wrong. The only correct statements are complex, interactive, and conditional. Group structure-organizations and networks-always matter, and qualitative differences in group structure make huge differences in the dynamics of collective action.

If one is trying to make simplistic predictions, all this complexity is a nightmare. But the complexity also shows the importance of human agency. Jasper (2004) argues that analysis of strategy clearly points to the role of leadership and agency in negotiating strategic dilemmas, as well as to the importance of the cultural and institutional contexts that shape strategic choices. Rational action theory does not deny agency but rather provides tools for understanding the dynamics of different strategic situations.

Consider the classic large group problem, clean air or clean water. It is impossible that the air or water supply will become cleaner through the independent actions of isolated individuals, and genuinely difficult and probably impossible to persuade enough individuals to change their habits to clean the air or water. But it is not at all impossible for concerned activists to get cleaner air and cleaner water through mobilizing an environmental movement and lobbying 
legislatures to pass laws that create water treatment plants, impose clean-up standards on polluting industries backed up by fines for noncompliance, mandate efficiency standards for vehicles and electrical appliances, and impose taxes and offer tax credits to shape desired consumer actions (Mitchell 1979). And, as Elinor Ostrom and her colleagues have amply demonstrated (Ostrom 1998, 1999), it is not at all impossible for traditional communities to organize themselves to preserve environmental resources across generations. There are explicable modes of social organization that make this possible. Rational actors transcend the dilemmas of individualized action by creating structures for collective action. They can use the results of formal theory to think about their strategic choices within their structural constraints. They can choose actions that require the resources and personnel they have. They can also use agency to change some of their structural constraints, for example by working to increase network ties among group members.

Many of the terms in rational action models are potentially endogenous or changeable. People can choose actions with different production functions, but they can also be persuaded to change their subjective interests or their perceptions of the likelihood of success of an action. New network ties can be created. These influence processes themselves can be and have been studied with the tools of formal analysis in the rational action tradition. Motivations that are not part of the standard rational action cost-benefit framework such as symbolic or expressive protest, or emotional dynamics, may well show influence patterns that are similar to those that have been found in models of the spread of ideas.

If theorizing is seen as a war between competing armies, it is important to wear uniforms and be sure friends and enemies can be distinguished. If theorizing is seen as an ecological competition for turf, then it is important to kill off pioneer members of species invading new terrain before they take over and choke off local species. If theorizing is a war of position in a profession, it is important to prevent other theorists from gaining any advantage and it is important to make distinctions. But if theorizing is seen as a cooperative enterprise that is trying to understand how the world works, it may not matter where the boundary of one theory ends and another begins. The rigorous tools developed in the rational action tradition have illuminated important processes in social movements that go far beyond the isolated economistic market-driven automaton that is the bugbear of some theorists in other traditions.

\section{References}

Ahlquist, J. S. and Levi, M. (2013). In the Interest of Others: Organizations and Social Activism. Princeton: Princeton University Press.

Berk, R. A. (1974). "A Gaming Approach to Crowd Behavior," American Sociological Review. 39: 355-73.

Carden, M. L. (1978). "The Proliferation of a Social Movement: Ideology and Individual Incentives in the Feminist Movement," Research in Social Movements, Conflicts and Change. 1: 179-96.

Centola, D. M. (2013). “Homophily, Networks, and Critical Mass: Solving the Start-up Problem in Large Group Collective Action," Rationality and Society. 25: 3-40. 
Centola, D. and Macy, M. (2007). "Complex Contagions and the Weakness of Long Ties," American Journal of Sociology. 113: 702-34.

Centola, D., Willer, R., and Macy, M. (2005). "The Emperor's Dilemma: A Computational Model of Self-Enforcing Norms." American Journal of Sociology. 110: 1009-40.

Chong, D. (1991). Collective Action and the Civil Rights Movement. Chicago: University of Chicago Press.

Clark, P. B. and Wilson, J. Q. (1961). "Incentive Systems: A Theory of Organizations," Administrative Science Quarterly. 6: 129-66.

Ferree, M. M. (1992). "The Political Context of Rationality: Rational Choice Theory and Resource Mobilization." In Frontiers in Social Movement Theory, edited by A. D. Morris and C. M. Mueller, 221-240 New Haven, Conn.: Yale University Press.

Finkel, S. E. and Muller, E. N. (1998). "Rational Choice and the Dynamics of Collective Political Action: Evaluating Alternative Models with Panel Data," American Political Science Review. 92: 37-49.

Finkel, S. E., Muller, E. N., and Opp, K.-D. (1989). "Personal Influence, Collective Rationality, and Mass Political Action," The American Political Science Review. 83: 885-903.

Francisco, R. A. (1995). "The Relationship between Coercion and Protest," Journal of Conflict Resolution. 39: 263-83.

Francisco, R. A. (2010). Collective Action Theory and Empirical Evidence. Dordrecht: Springer.

Frohlich, N., Hunt, T., Oppenheimer, J., and Wagner, R. H. (1975). "Individual Contributions for Collective Goods: Alternative Models," The Journal of Conflict Resolution. 19: 310-29.

Frohlich, N. and Oppenheimer, J. A. (1970). "I Get by with a Little Help from My Friends," World Politics. 23: 104-20.

Gould, R. V. (1993). "Collective Action and Network Structure," American Sociological Review. 58: 182-96.

Granovetter, M. (1978). "Threshold Models of Collective Behavior," American Journal of Sociology. 83: 1420-43.

Granovetter, M. and Soong, R. (1983). "Threshold Models of Diffusion and Collective Behaviour," Journal of Mathematical Sociology. 9: 165.

Hechter, M. (1992). "The Insufficiency of Game Theory for the Resolution of Real-World Collective Action Problems," Rationality \& Society. 4: 33-40.

Hechter, M. and Okamoto, D. (2001). "Political Consequences of Minority Group Formation," Annual Review of Political Science. 4: 189-215.

Heckathorn, D. D. (1996). "The Dynamics and Dilemmas of Collective Action," American Sociological Review. 61: 250-77. 
Heckathorn, D. D. (1998). "Collective Action, Social Dilemmas and Ideology," Rationality and Society. 10: 451-80.

Hoover, D. and Kowalewski, D. (1992). "Dynamic Models of Dissent and Repression," Journal of Conflict Resolution. 36: 150-82.

Janssen, M. (2011). "Targeting Individuals to Catalyze Collective Action in Social Networks," Computational Social Science Society of the Americas.

Jasper, J. M. (2004). "A Strategic Approach to Collective Action: Looking for Agency in SocialMovement Choices," Mobilization. 9: 1-16.

Kerner, O., Lindsay, J. V., and Harris, F. (1968). Report of the National Advisory Commission on Civil Disorders. Washington DC: US Government Printing Office.

Kim, H. and Bearman, P. S. (1997). "The Structure and Dynamics of Movement Participation," American Sociological Review. 62: 70-93.

Kitts, J. A. (2006). "Collective Action, Rival Incentives, and the Emergence of Antisocial Norms," American Sociological Review. 71: 235-59.

Kitts, J. A. (2008). "Dynamics and Stability of Collective Action Norms," Journal of Mathematical Sociology. 32: 142-63.

Klandermans, B. (1988). "Union Action and the Free-Rider Dilemma," Research in Social Movements, Conflicts and Change. 10: 77-91.

Klandermans, B. (2002). "How Group Identification Helps to Overcome the Dilemma of Collective Action," American Behavioral Scientis.,45: 887.

Klandermans, B. and Oegema, D. (1987). "Potentials, Networks, Motivations and Barriers: Steps Towards Participation in Social Movements," American Sociological Review. 52: 519-31.

Klandermans, B., Van Der Toorn, J., and Van Stekelenburg, J. (2008). “Embeddedness and Identity: How Immigrants Turn Grievances into Action," American Sociological Review. 73: 9921012.

Klosko, G., Muller, E. N., and Opp, K. D. (1987). "Rebellious Collective Action Revisited," The American Political Science Review. 81: 557-564.

Koopmans, R. (2005). "The Missing Link between Structure and Agency: Outline of an Evolutionary Approach to Social Movements," Mobilization: An International Journal. 10: 19-35.

Lichbach, M. I. (1995). The Rebel's Dilemma. Ann Arbor, University of Michigan Press.

Lichbach, M. I. (1996). The Cooperator's Dilemma. Ann Arbor, University of Michigan Press.

Lichbach, M. I.( 2003). Is Rational Choice Theory All of Social Science? Ann Arbor, University of Michigan Press.

Macy, M. W. (1990). "Learning Theory and the Logic of Critical Mass," American Sociological Review. 55: 809-26. 
Macy, M. W. (1991). "Chains of Cooperation: Threshold Effects in Collective Action," American Sociological Review. 56: 730-47.

Marwell, G. and Oliver, P. (1993). The Critical Mass in Collective Action: A Micro-social Theory. Cambridge, New York: Cambridge University Press.

Marwell, G., Oliver, P. E., and Prahl, R. (1988). "Social Networks and Collective Action: A Theory of the Critical Mass. III," American Journal of Sociology, 94: 502-34.

Marx, G. T. (1970). "Issueless Riots," The Annals of the American Academy of Political and Social Science. 391: 21-33.

McCarthy, J. D. and Zald, M. N. (1973). The Trend of Social Movements in America: Professionalization and Resource Mobilization. Morristown, NJ, General Learning Press.

McCarthy, J. D. and Zald, M. N. (1977). "Resource Mobilization and Social Movements: A Partial Theory," American Journal of Sociology. 82: 1212-41.

McPhail, C. (1969). "Student Walkout: A Fortuitous Examination of Elementary Collective Behavior," Social Problems. 16: 441-55.

McPhail, C. (1971). "Civil Disorder Participation: A Critical Examination of Recent Research," American Sociological Review. 36: 1058-73.

McPhail, C. (1991). The Myth of the Madding Crowd, New York, Walter DeGruyter.

McPhail, C. (1994). "The Dark Side of Purpose: Individual and Collective Violence in Riots," Sociological Quarterly. 35: 1-32.

McPhail, C. and Miller, D. (1973). "The Assembling Process: A Theoretical and Empirical Examination," American Sociological Review. 38: 721-35.

McPhail, C. and Wohlstein, R. T. (1983). "Individual and Collective Behaviors Within Gatherings, Demonstrations, and Riots," Annual Review of Sociology. 9: 579.

Melucci, A. (1985). "The Symbolic Challenge of Contemporary Movements," Social Research. 52: 789-816.

Melucci, A. (1988). "Getting Involved: Identity and Mobilization in Social Movements," International Social Movement Research. 1: 329-48.

Melucci, A. (1995). "The Process of Collective Identity." In Social Movements and Culture, edited by $\mathrm{H}$. Johnston and B. Klandermans, 41-63. Minneapolis, MN: U of Minnesota Press.

Mitchell, R. C. (1979). "National Environmental Lobbies and the Apparent Illogic of Collective Action." In Collective Decision Making: Applications From Public Choice Theory, edited by C. S. Russell, xxx. Baltimore: Johns Hopkins University Press.

Muller, E. N. and Opp, K.-D. (1986). "Rational Choice and Rebellious Collective Action," The American Political Science Review. 80: 471-88. 
Oberschall, A. (1973). Social Conflict and Social Movements. Englewood Cliffs., N.J.,, PrenticeHall.

Oberschall, A. (1978). "Theories of Social Conflict," Annual Review of Sociology. 4: 291-315.

Oliver, P. (1980). "Rewards and Punishments as Selective Incentives for Collective Action: Theoretical Investigations," American Journal of Sociology. 85: 1356-75.

Oliver, P. E. (1993). "Formal Models of Collective Action," Annual Review of Sociology. 19: 271300.

Oliver, P. E. and Marwell, G. (1988). "The Paradox of Group Size in Collective Action: A Theory of the Critical Mass. II," American Sociological Review. 53: 1-8.

Oliver, P., Marwell, G., and Teixeira, R. (1985). "A Theory of the Critical Mass. I.

Interdependence, Group Heterogeneity, and the Production of Collective Action," American Journal of Sociology. 91: 522-56.

Oliver, P. E. and Myers, D. J. (2003). "The Coevolution of Social Movements," Mobilization. 8: 124.

Olson, M. (1965). The Logic of Collective Action; Public Goods and the Theory of Groups. Cambridge, MA: Harvard University Press.

Opp, K.-D. (1988). "Grievances and Participation in Social Movements," American Sociological Review. 53: 853-64.

Opp, K.-D. (1990). "Postmaterialism, Collective Action, and Political Protest," American Journal of Political Science. 34: 212.

Opp, K.-D. (1994). "Repression and Revolutionary Action: East Germany in 1989," Rationality \& Society. 6: 101-38.

Opp, K.-D. (1999). "Contending Conceptions of the Theory of Rational Action," Journal of Theoretical Politics. 11: 171.

Opp, K.-D. (2000). “Adverse Living Conditions, Grievances, and Political Protest after Communism: The Example of East Germany," Social Forces. 79: 29-71.

Opp, K.-D. (2004). "How Does Postcommunist Transformation Affect Political Protest? The Example of East Germany," Mobilization: An International Journal. 9: 127-47.

Opp, K.-D. (2009). “Das individualistische ErklÃßrungsprogramm in der Soziologie. Entwicklung, Stand und Probleme," (German). The Individualistic Research Program in Sociology.

Development, Present State, and Problems. (English). 38: 26-47.

Opp, K.-D. and Roehl, W. (1990). "Repression, Micromobilization, and Political Protest," Social Forces. 69: 521-47.

Ostrom, E. (1998). "A Behavioral Approach to the Rational Choice Theory of Collective Action Presidential Address," American Political Science Review. 92: 1-22. 
Ostrom, E. (1999). "Coping With Tragedies of the Commons," Annual Review of Political Science. 2: 493-535.

Pierskalla, J. H. (2010). "Protest, Deterrence, and Escalation: The Strategic Calculus of Government Repression," Journal of Conflict Resolution. 54: 117-45.

Prahl, R., Marwell, G. , and Oliver, P. E. (1991). "Reach and Selectivity as Strategies of Recruitment for Collective Action: A Theory of the Critical Mass, V," The Journal of Mathematical Sociology. 16: 137-64.

Schelling, T. C. (1973). "Hockey Helmets, Concealed Weapons, and Daylight Saving: A Study of Binary Choices with Externalities," Journal of Conflict Resolution. 17: 381-428.

Schwartz, M. (1976). Radical Protest and Social Structure: The Southern Farmers' Alliance and Cotton Tenancy, 1880-1890. New York, Academic Press.

Siegel, D. A. (2009). "Social Networks and Collective Action," American Journal of Political Science. 53: 122-38.

Singer, B. D. (1968). "Mass Media and Communication Process in the Detroit Riot of 1967," Public Opinion Quarterly. 34: 236-45.

Singer, B. D., Geschwender, J. A., and Osborn, R. W. (1970). Black Rioters; A Study of Social Factors and Communication in the Detroit Riot. Lexington, MA: Heath Lexington Books.

Sullivan, T. J. (1977). "The 'Critical Mass' in Crowd Behavior: Crowd Size, Contagion and the Evolution of Riots," Humboldt Journal of Social Relations. 4: 46-59.

Tilly, C. (1978). From Mobilization to Revolution. Reading, MA: Addison-Wesley.

Wilson, J. Q. (1974). Political Organizations. New York: Basic Books. 